\title{
(BI)SULFATE ADSORPTION ON QUASI PERFECT Pt(111) FACETS FROM ACIDIC AQUEOUS ELECTROLYTES AS MONITORED BY OPTICAL TECHNIQUES
}

\author{
Iosif Fromondi and Daniel Scherson
}

\section{SUPPLEMENTARY MATERIAL}

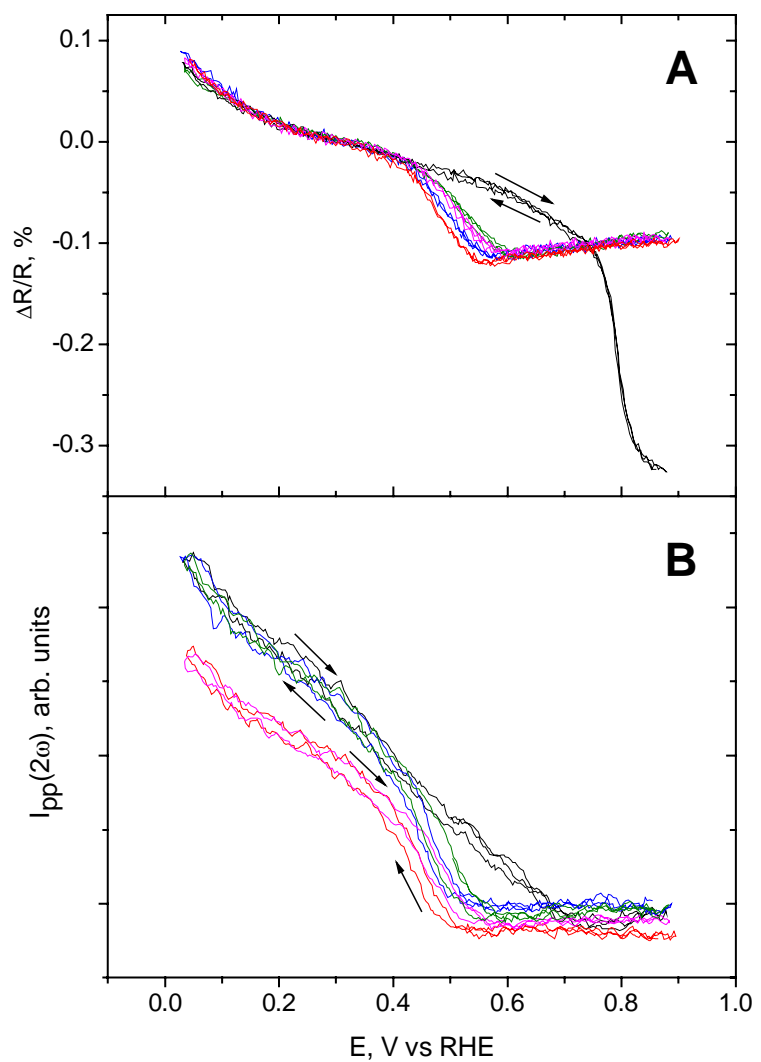

Fig. S.1. Plots of $\Delta R / R\left(E_{\text {ref }}=0.35 V\right.$, Panel A) and $I_{p p}(2 \omega)$ vs potential (Panel B) for a $\mathrm{Pt}(111)$ microfacet in $0.1 \mathrm{M} \mathrm{HClO}_{4}+x \mathrm{M} \mathrm{H}_{2} \mathrm{SO}_{4}$ where $x=0$ (black), $3.75 \times 10^{-4}$ (green), $1 \times 10^{-3}$ (magenta), $3.75 \times 10^{-3}$ (blue), $1 \times 10^{-2} \mathrm{M}$ (red). Scan rate, $v=2 \mathrm{~V} / \mathrm{s}$. The plots are raw data and they represent ca 700 acquisitions each. 


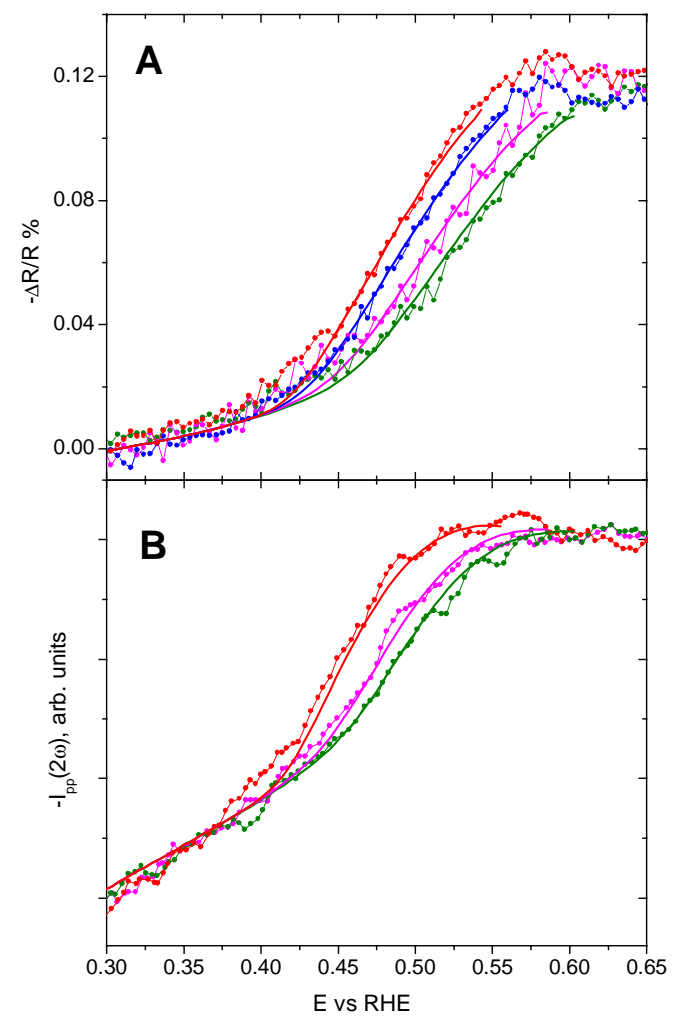

Fig. S.2. Plots of experimental $-\Delta R / R\left(E_{\text {ref }}=0.35 V\right.$, scattered, panel $\left.A\right)$, calculated $\Delta R / R$ (solid line, panel A), experimental $-\mathrm{I}_{\mathrm{pp}}(2 \omega)$ (scattered, panel B) and calculated $-\mathrm{I}_{\mathrm{pp}}(2 \omega) \mathrm{vs}$ potential (solid line, panel B) based on the (bi)sulfate coverage and the model proposed (see text for details) for a $\mathrm{Pt}(111)$ microfacet in $0.1 \mathrm{M} \mathrm{HClO}_{4}+x \mathrm{M} \mathrm{H}_{2} \mathrm{SO}_{4}$, where $x=0$ (black), $3.75 \times 10^{-4}$ (green), $1 \times 10^{-3}$ (magenta), $1 \times 10^{-2} \mathrm{M}$ (red). For other conditions, see caption Fig.1. 